\title{
Leucine zipper transcription factor-like 1 expression in gastric cancer and its relationship to relative adhesion molecule
}

\author{
Lian Xiaowen ${ }^{1,2}$, Li Kesheng ${ }^{2}$, Du Huifen², Li Xingwen³ ${ }^{3}$ Cui Yan*, Chai Dandan³, \\ Xu Yang ${ }^{2}$ and Yang Rong ${ }^{4}$ \\ ${ }^{1}$ College of Veterinary Medicine, Gansu Agricultural University, ${ }^{2}$ Department of Medicine Biotechnology, Medicine and Science \\ Research Institute, ${ }^{3}$ Department of Surgery, Tumor Hospital of Gansu Province, ${ }^{4}$ Department of Pathology Gansu Provincial \\ Tumor Hospital
}

*For correspondence: Email: cuiyangau@163.com

\begin{abstract}
Purpose: To evaluate the expression of leucine zipper transcription factor-like1 (LZTFL1) molecule in the gastric cancer tissues, and its relationship to cellular adhesion protein.

Methods: Expressions of LZTFLI, E-cadherin, $\beta$-catenin, intercellular cell adhesion molecule-1(ICAM-1) as well as vascular cell adhesion molecule-1 (VCAM-1) in the 133 gastric cancer samples and 40 gastritis samples were evaluated by immunohistochemistry. Levels of mRNA in gastric cancer and latero-cancer tissue were determined by real-time polymerase chain reaction (RT-PCR).

Results: Protein levels in gastric tissue decreased. The expression of LZTFL1in gastric cancer tissue correlated with tumor stage (tumor node metastasis staging), degree of tumor differentiation and invasion depth $(p<0.05)$. Protein expression correlated with $E$-cadherin positively, and correlated with $\beta$-catenin and ICAM-1 negatively, but had no correlation with VCAM-1. Compared with tissues remote to the cancer, mRNA level of LZTFL1 in gastric cancer decreased significantly. There was no significant difference in LZTFL1 mRNA levels in the various clinical pathological tissues. LZTFL1 mRNA expression did not correlation with various adhesion factors.

Conclusion: LZTFL1 is expressed at a low level in gastric cancer tissue. Its protein expression is related to cellular adhesion protein, but not to mRNA level. As a suppressor of invasion of cancer cells, LZTFL1 may be a potential target for targeted therapy of gastric cancer.
\end{abstract}

Keywords: Leucine zipper transcription factor-like1 expression, Gastric cancer, Relative adhesion molecule, Protein expression

Tropical Journal of Pharmaceutical Research is indexed by Science Citation Index (SciSearch), Scopus, International Pharmaceutical Abstract, Chemical Abstracts, Embase, Index Copernicus, EBSCO, African Index Medicus, JournalSeek, Journal Citation Reports/Science Edition, Directory of Open Access Journals (DOAJ), African Journal Online, Bioline International, Open-J-Gate and Pharmacy Abstracts

\section{INTRODUCTION}

It has been reported that gastric cancer (GC) is one of the most common malignant tumors [1]. It contributes significantly to global cancer death $[2,3]$. Metastasis of $\mathrm{GC}$ is a key factor responsible for high fatality rate in GC patients $[4,5]$. The aetiology of $\mathrm{GC}$ is a complex process involving multiple genes. Mutation and loss of tumor suppressor gene can promote invasion and metastasis of tumors [6].

LZTFL1 is a 299 amino acid-residue tumor suppressor molecule of molecular weight $34.6 \mathrm{KD}$ [7]. It is expressed in low amounts in multiple malignant tumors, and is correlated with gastric, NSCLC and liver cancers $[8,9]$. Studies have shown that in GC, LZTFL1 is correlated with 
adhesion factors induced by E-cadherin [8]. Research demonstrated that LZTFL1 is correlated with Integrin $\beta 1$ in liver cancer cells. Indeed LZTFL1 can participate in invasion and metastasis of hepatocellular carcinoma by regulating integrin $\beta 1$ expression. These reports show that LZTFL1, as an inhibitory factor of cancer cellular invasion and metastasis, probably affects migration of cells through cellular adhesion protein.

Members of cellular adhesion protein are numerous. E-cad is an important member of type I in CD family. In adult tissue, E-cad promotes inter-adhesion of epithelial cells and maintains their integrity and epithelial polarity of their organization structure[10]. E-cad inhibits tumor occurrence and metastasis. Loss of E-cad CDH1 in tumor cells increases their potential for invasion and metastasis [11]. $\beta$-Catenin participates in cadherin-mediated inter-cellular adhesion, and provides a link between extracellular adhesion sites and actin via $\alpha$ catenin ( $\alpha$-cat). It is an important cellular adhesion molecule, a vital cellular skeletal ingredient, and an important component of Wnt signal pathway. Abnormalities in intracellular location of $\beta$-catenin in tumor cells lead to decreases in expression of $\beta$-catenin envelope, thereby reducing inter-cellular adhesion and promoting invasion and metastasis $[12,13]$.

ICAM-1, VCAM-1 and CD106 belong to immunoglobulin superfamily. ICAM-1 promotes inter-adhesion of tumor cells and vascular endothelial cells [14]. Thus VCAM-1 participates in metastasis of cancer cells as a co-stimulatory molecule [15].

The present study was aimed at investigating the correlation between LZTFL1 and different adhesion molecules in patients with GC.

\section{EXPERIMENTAL}

\section{Clinical samples}

All GC and benign gastric disease samples used in this study came from patients who underwent excision from 2011 to 2014 in Gansu Provincial Cancer Hospital, China. The patients were not given radiotherapy and chemotherapy before tumorectomy. Fresh samples of GC $(n=59)$ and corresponding non-cancerous tissue (taken $5 \mathrm{~cm}$ distance from cancerous lesions) were excised and stored at $-80{ }^{\circ} \mathrm{C}$ for RNA extraction. Relevant clinical data of patients were collected from pathological reports and from investigating outpatient cases. Features of patients and tumor are summarized in Table 1. All patients had complete medical records and follow-up data, and they signed consent form approved by the Hospital's Ethics Committee (approval certificate no. P201108150024). This research was conducted according to the Declaration of Helsinki promulgated in 1964, as amended in 1996 [16].

\section{Immuno-histochemical analyses of samples}

Samples were fixed in $10 \%$ formalin and then were embedded. Slices of $4 \mu \mathrm{m}$ thickness were produced using a microtome.

Table 1: Clinico-pathological features of patients

\begin{tabular}{|c|c|c|c|}
\hline \multirow[t]{2}{*}{ Clinico-pathologic feature } & \multicolumn{2}{|c|}{ IHC staining } & \multirow{2}{*}{$\begin{array}{c}\text { RT-PCR } \\
\text { Gastric cancer ( \%) }\end{array}$} \\
\hline & Gastric cancer ( \%) & Gastritis ( \%) & \\
\hline $\begin{array}{l}\text { Case no. } \\
\text { Gender }\end{array}$ & 133 & 40 & 59 \\
\hline Male & $98(74)$ & $20(50)$ & $44(75)$ \\
\hline $\begin{array}{l}\text { Female } \\
\text { Age (vr) }\end{array}$ & $35(26)$ & $20(50)$ & $15(25)$ \\
\hline$<60$ & $78(59)$ & $27(69)$ & $32(55)$ \\
\hline$\geq 60$ & $55(41)$ & $12(31)$ & $26(45)$ \\
\hline Mean $( \pm S D)$ & $55.85( \pm 10.63)$ & $52.90( \pm 13.85)$ & $57.44( \pm 9.26)$ \\
\hline Tissue differentiation & & & \\
\hline Well/moderately & $78(68)$ & & $37(70)$ \\
\hline $\begin{array}{l}\text { Poorly/undifferentiated } \\
\text { Clinical stages }\end{array}$ & $37(32)$ & & $16(30)$ \\
\hline$|-| \mid$ & $49(42)$ & & $19(37)$ \\
\hline $\begin{array}{l}\text { III-IV } \\
\text { Lymph node metastasis }\end{array}$ & $69(58)$ & & $33(63)$ \\
\hline Absent & $38(31)$ & & $15(27)$ \\
\hline Present & $85(69)$ & & $40(73)$ \\
\hline
\end{tabular}


The expressions of VCAM-1, LZTFL1, $\beta$-catenin, $\mathrm{E}$-cadherin, and ICAM-1 in the clinical samples were determined by immuno-histochemical staining using SP-9000 Histostain TM Plus kits (ZYMED, South San Francisco, USA). The concentration of the first antibody was $3 \mu \mathrm{g} / \mathrm{ml}$. Negative control was PBS, which substituted for the first antibody.

The immuno-histochemical scores were given by two independent pathologists naïve to the clinical information on the samples scored. Score standards were measured by Sinicrope [12]. Positive results were based on percentage of staining multiplied by positive cells ( $\geq 4$ positive, $<4$ negative). Intensity of staining was scored as follows: (d) $0=$ no staining (c) 1 = light; (b) $2=$ moderate staining; and (a) $3=$ strong staining. Percentage scores for positive cells were graded as follows: (e) $<5 \%=0$; (d) $5-25 \%=1$; (c) 25 $-50 \%=2$; (b) $50-75 \%=3$; and (a) $>75 \%=4$.

\section{Fluorescent quantitative measurement of total RNA}

Total tissue RNA was extracted through Trizol reagent (Takara Biotechnology, China). Its concentration and purity were determined spectrophotometrically. RNA was transformed into cDNA using PrimeScript ${ }^{\mathrm{TM}} \mathrm{RT}$ kits (Takara Biotechnology, Dalian, China). RNA addition and system configuration followed assay kit requirements. Premix Ex TaqTM II kits (Takara Biotechnology, Dalian, China) were used for realtime PCR to measure mRNA expression. The experimental procedures were in line with instructions in the assay kits. GAPDH was used as internal reference. Relative gene expression was calculated by $2-\Delta \Delta \mathrm{Ct}$ method. The primers used are shown in Table 2.

\section{Statistical analysis}

All real-time data were collected and presented as Mean \pm SD. Data were analyzed with ANOVA or t-test as appropriate. Calculation and analyses were done using IBM SPSS 19.0. Differences between LZTFL1 and clinical pathological features of GC were analyzed using chi-square test. Correlations between LZTFL1 and expressions of E-cadherin, $\beta$-catenin, VCAM-1 and VCAM-1were analyzed through Spearman's rank correlation coefficient. $P<0.05$ was taken as indicative of significant differences statistically.

\section{RESULTS}

VCAM-1, ICAM-1, E-cadherin, LZTFL1, $\beta$ catenin and protein expression in clinical samples

The levels of VCAM-1, LZTFL1, $\beta$-catenin, Ecadherin and ICAM-1 of 133 gastric cancer tissues embedded in paraffin, and 40 gastritis tissue samples were measured by immunohistochemical staining. The results showed that the expressions of LZTFL1, $\beta$-catenin and Ecadherin in GC tissue were lower than those in gastritis tissue $(p<0.05)$. The expression of VCAM-1 $(p<0.05)$ was much higher. There was no significant difference in the expressions of VCAM-1 between GC tissue and gastritis tissue (Table 3). Some typical cases are shown in Figure 1.

Table 2: Primer series of relevant genes

\begin{tabular}{lll}
\hline Gene & Upstream primer5'-3' & Downstream primer 5'-3' \\
\hline LZTFL1 & ATTGGAGCATAGGGCTTGTTGT & AAGGGCACAGAAACTGGTAAGTG \\
E-cadherin & GAGTGCCAACTGGACCATTCAGTA & AGTCACCCACCTCTAAGGCCATC \\
ICAM-1 & TGTATGAACTGAGCAATGTGCAAGA & CACCTGGCAGCGTAGGGTAA \\
VCAM-1 & GGCGCCTATACCATCCGAAA & AGAGCACGAGAAGCTCAGGAGAA \\
B-catenin & TGGCACCCAGCACAATGAA & CTAAGTCATAGTCCGCCTAGAAGCA \\
GAPDH & TGTATGAACTGAGTGTGCAAGA & CACCTGGCAGCGTAGTAA \\
\hline
\end{tabular}

Table 3: Expressions of LZTFL1, E-cadherin, $\beta$-catenin, ICAM-1 and VCAM-1 in clinical samples

\begin{tabular}{|c|c|c|c|c|c|c|c|}
\hline \multirow{2}{*}{ Protein } & \multicolumn{3}{|c|}{ Gastric cancer } & \multicolumn{3}{|c|}{ Gastritis } & \multirow{2}{*}{$\begin{array}{c}P- \\
\text { value }\end{array}$} \\
\hline & $N$ & Positive & PR (\%) & $N$ & Positive & $P R(\%)$ & \\
\hline LZTFL1 & 133 & 49 & 37 & 40 & 26 & 65 & ** \\
\hline$\beta$-catenin & 128 & 73 & 57 & 37 & 30 & 81 & ** \\
\hline $\mathrm{E}-\mathrm{CD}$ & 130 & 35 & 27 & 39 & 28 & 72 & ** \\
\hline ICAM-1 & 128 & 99 & 77 & 38 & 27 & 71 & 0.42 \\
\hline VCAM-1 & 133 & 57 & 43 & 40 & 10 & 25 & \\
\hline
\end{tabular}

Note: ${ }^{\star} P<0.05,{ }^{* \star} p<0.01$. $\mathrm{PR}=$ positive rate 


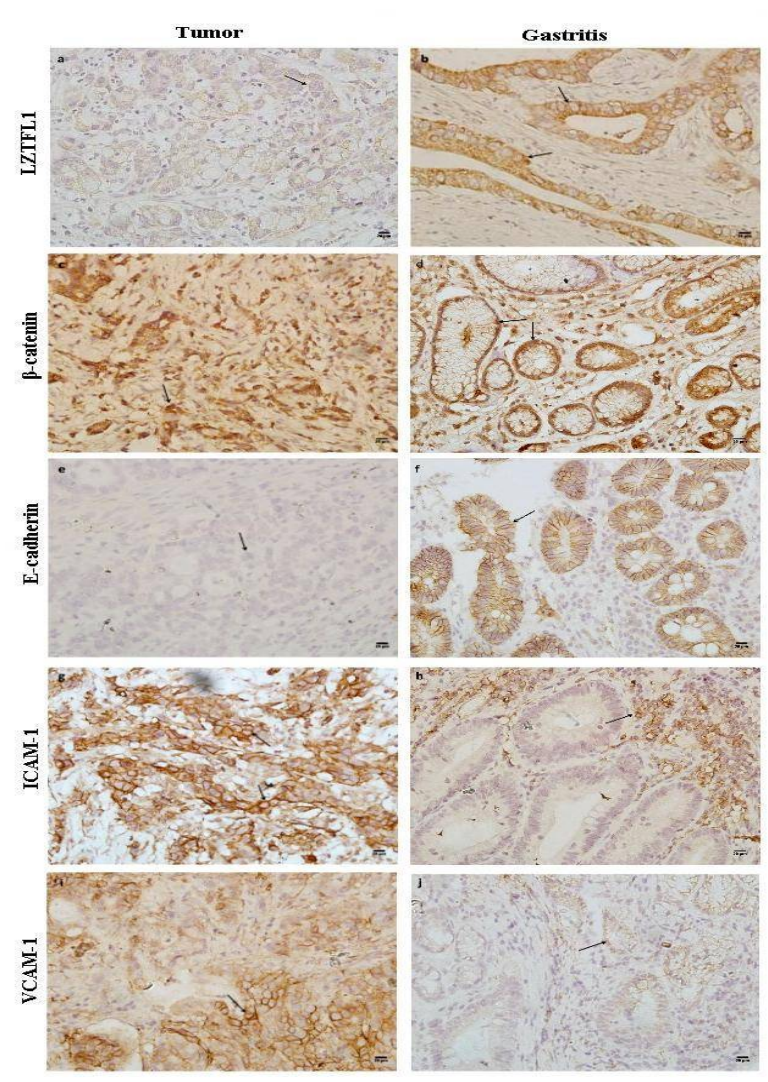

Figure 1: IHC analysis of the expression of LZTFL1, $\beta$-catenin, E-cadherin, ICAM-1 and VCAM-1 (X 200). Note: The expressions of LZTFL1 in gastric carcinoma tissues were low (a) and highly expressed in the gastritis tissues (b). The expressions of $\beta$-catenin in the gastric cancer tissues (c) was ectopic (pulp / nuclear) or not (d); E-cadherin was not expressed in gastritis tissues (f), but not in gastritis tissues gastric cancer tissues, and was highly expressed; ICAM1 was expressed highly in the gastric carcinoma (g) and locally expressed in gastritis tissues (h); VCAM-1 was highly expressed in the gastric cancer tissues (i) and low / non-expressed in gastritis tissues (j)

\section{Correlation between LZTFL1, E-cadherin, $\beta$ - catenin, ICAM-1 and VCAM-1 and pathologi- cal features of gastric cancer patients}

LZTFL1 expression in GC tissue was positively correlated with tumor stage and degree of tumor differentiation $(p<0.05)$, volume of tumor primary site and size of affected adjacent tissue $(p<0.01)$. However, it was not with tumor size ( $p$ $>0.05$ ). There were no significant differences in LZTFL1 between GC-with-lymph metastasis group and non-metastasis group $(p>0.05)$. There were also no significant differences in age and sex of the GC patients. B-catenin expression in well-differentiated GC tissue was higher than in low-differentiated or undifferentiated tissue ( $p$ $<0.05$ ). E-cadherin expression rate decreased along with increase in tumor stage (TNM staging).

Expression of E-cadherin in well-differentiated GC group was higher than in low differentiated or undifferentiated tissue $(p<0.05)$, but its expression in GC-with-lymph-metastasis group was significantly lower than that in the nonmetastasis group $(p<0.05)$. ICAM-1 and VCAM1 expressions in GC patients with lymph metastasis were significantly higher than corresponding values in non-metastasis group ( $p$ $<0.05$ ), but there were no significant differences in the other groups $(p>0.05)$.

\section{LZTFL1, E-cadherin, $\beta$-catenin, ICAM-1 and VCAM-1 mRNA expression in clinical samples}

Levels of mRNAs of LZTFL1, E-cadherin, $\beta$ catenin, ICAM-1 and VCAM-1 in 59 fresh GC tissues and their corresponding non-cancerous tissues were determined by qRT-PCR. The results showed that mRNA levels of LZTFL1, Ecadherin in GC tissue were significantly decreased when compared with corresponding paired, non-cancerous tissue. There were no significant differences in mRNA expression levels of $\beta$-catenin, ICAM-1 and VCAM-1 mRNA (Figure 2). In addition, there were no significant differences in LZTFL1 mRNA expression among different groups with clinical/pathological features $(p>0.05$, Table 5$)$.

\section{Correlation between LZTFL1 and adhesion factors}

The results of correlation analysis showed that LZTFL1 protein expression was positively correlated with E-cadherin, and negatively correlated with $\beta$-catenin and ICAM-1. Expression of LZTFL1 mRNA had no correlation with various adhesion molecules. The results of correlation analysis between LZTFL1 and various adhesion molecules are shown in Table 6.

\section{DISCUSSION}

The results obtained in this study showed that LZTFL1 in epithelial cells of normal tissues was highly expressed, but was lowly expressed in samples of corresponding invasive cancer group [7]. LZTFL1 expression is of prognostic significance in GC. In vitro studies have shown that the expression of LZTFL1 in tumor tissue can inhibit metastasis of tumor cells [8]. 
Table 4: Expressions of LZTFL1, E-cadherin, $\beta$-catenin, ICAM-1 and VCAM-1 protein and clinicpathological parameters in GC tissues

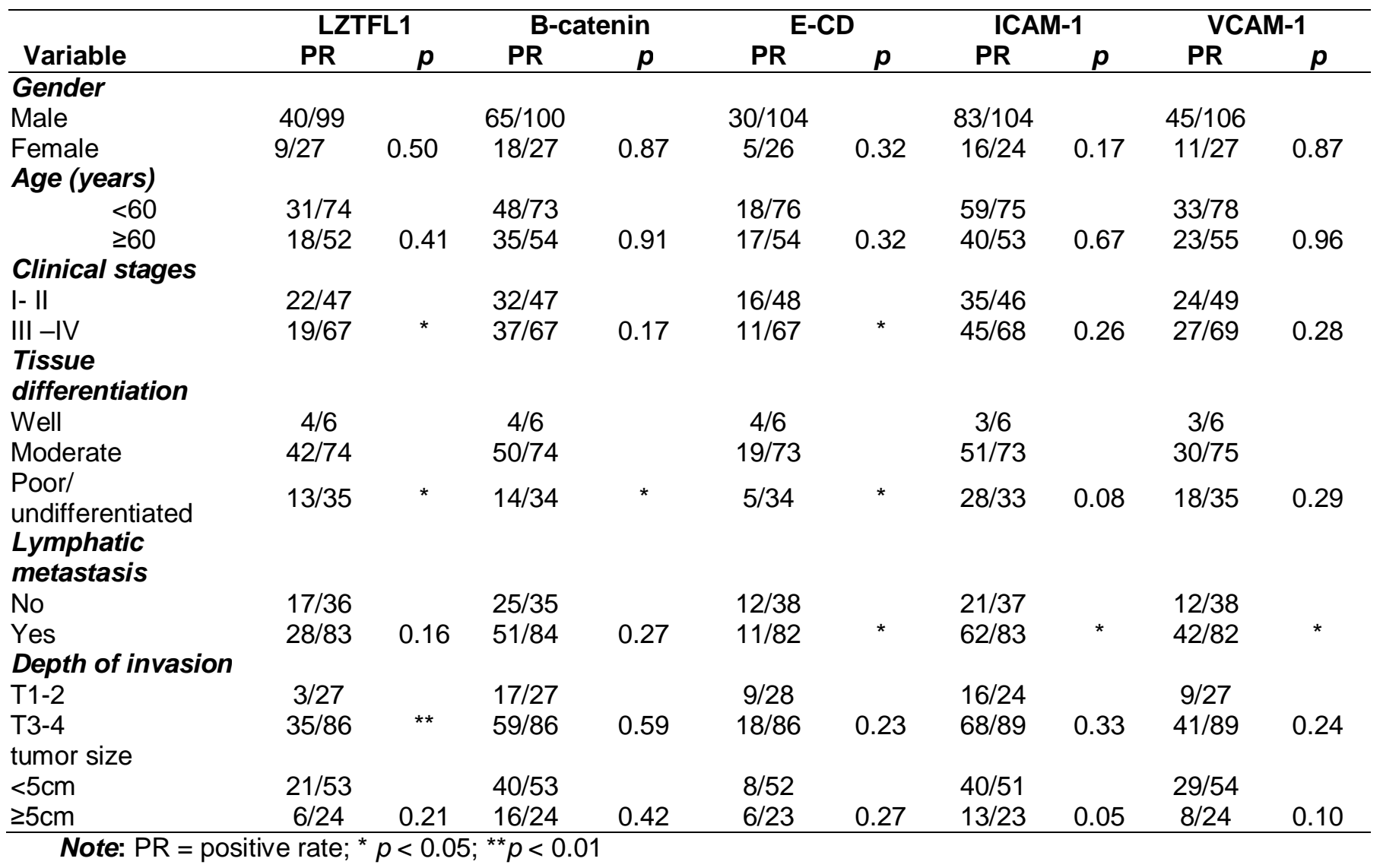

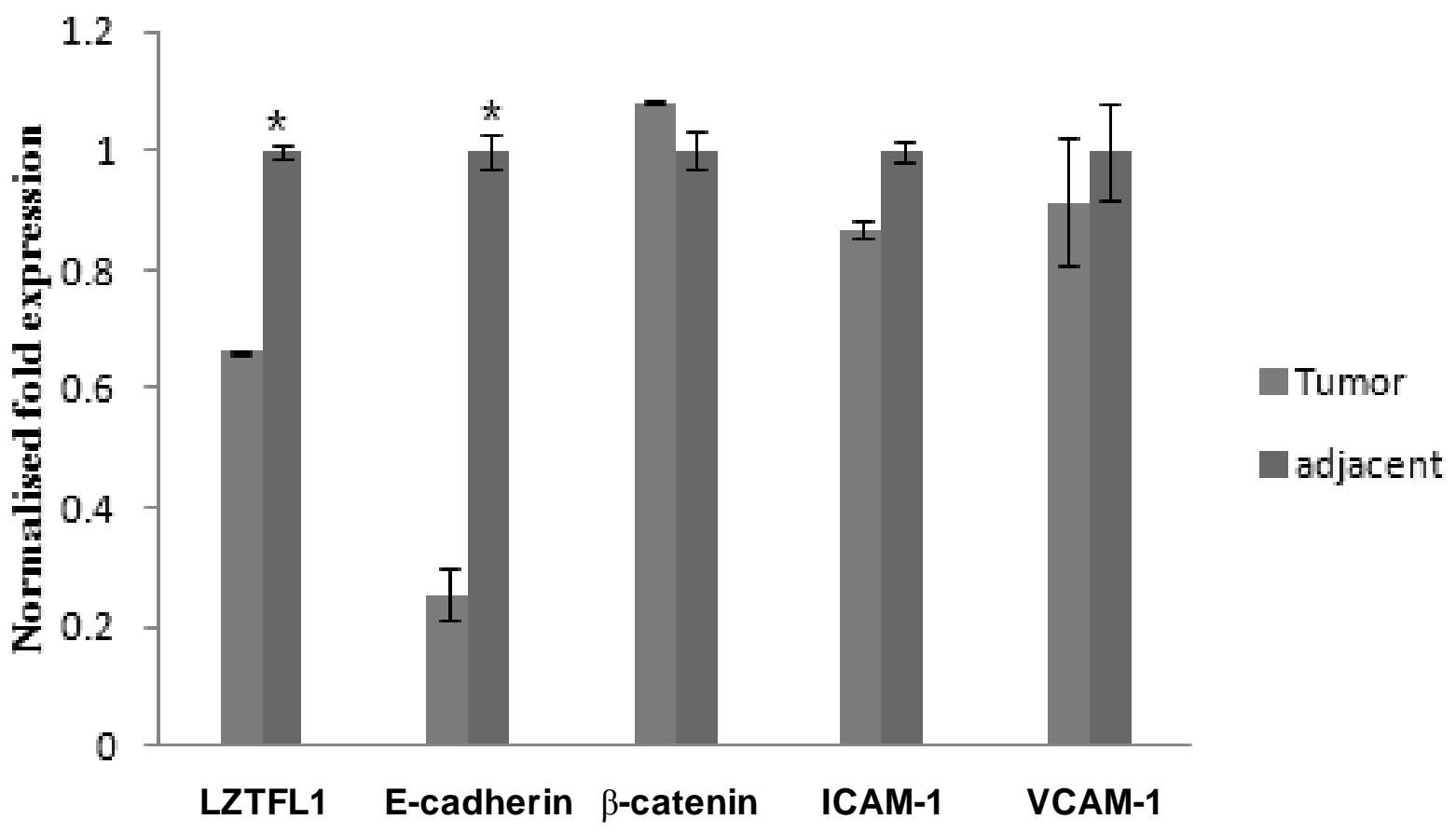

Figure 2: Expression of mRNA in adjacent non-cancerous tissues and in paired GC tissues by Realtime PCR. ${ }^{*} p>0.05$ (paired Student t-test) 
Table 5: Expression of LZTFL1 transcripts and correlation between LZTFL1 and clinic-pathological parameters in GC tissues

\begin{tabular}{|c|c|c|c|c|}
\hline \multirow{2}{*}{ Variable } & \multicolumn{3}{|c|}{ LZTFL1 } & \multirow{2}{*}{$P$-value } \\
\hline & $T / N>2$ & $T / N 2-0.5$ & $T / N<0.5$ & \\
\hline \multicolumn{5}{|l|}{ Age (years) } \\
\hline$<60$ & 9 & 6 & 17 & \multirow{2}{*}{0.627} \\
\hline$\geq 60$ & 5 & 4 & 17 & \\
\hline \multicolumn{5}{|l|}{ Gender } \\
\hline Male & 8 & 7 & 28 & \multirow{3}{*}{0.183} \\
\hline Female & 6 & 3 & 6 & \\
\hline \multicolumn{4}{|l|}{ Tumor size $(\mathrm{cm})$} & \\
\hline$<5 \mathrm{~cm}$ & 6 & 7 & 22 & \multirow{2}{*}{0.524} \\
\hline$\geq 5 \mathrm{~cm}$ & 5 & 2 & 10 & \\
\hline \multicolumn{5}{|l|}{ Tissue differentiation } \\
\hline Well & 3 & 2 & 8 & \multirow{4}{*}{0.614} \\
\hline Moderate & 5 & 6 & 12 & \\
\hline Poor/undifferentiated & 4 & 1 & 11 & \\
\hline \multicolumn{4}{|l|}{ Depth of invasion } & \\
\hline $\mathrm{T} 1+\mathrm{T} 2$ & 2 & 3 & 8 & \multirow{2}{*}{0.638} \\
\hline $\mathrm{T} 3+\mathrm{T} 4$ & 9 & 5 & 23 & \\
\hline \multicolumn{5}{|c|}{ Lymph node metastasis } \\
\hline No & 3 & 3 & 8 & \multirow{2}{*}{0.886} \\
\hline Yes & 11 & 7 & 22 & \\
\hline \multicolumn{5}{|l|}{ TNM staging } \\
\hline I+II & 2 & 2 & 15 & \multirow{2}{*}{0.174} \\
\hline $\mathrm{III+IV}$ & 9 & 6 & 17 & \\
\hline
\end{tabular}

Table 6: Correlation between expressions of LZTL1 and adhesion molecules in IHC and PCR

\begin{tabular}{lcccccc}
\hline Variable & \multicolumn{2}{c}{ IHC } & & \multicolumn{2}{c}{ PCR } \\
\cline { 2 - 3 } \cline { 5 - 7 } & $\boldsymbol{R}$ & $\boldsymbol{P}$-value & & $\boldsymbol{R}$ & $\boldsymbol{P}$-value \\
\hline B-catenin & -0.24 & & $* *$ & & -0.02 & 0.87 \\
E-cadherin & 0.17 & & $* *$ & & 0.20 & 0.14 \\
ICAM-1 & -0.12 & & $* *$ & & -0.04 & 0.77 \\
VCAM-1 & -0.01 & & 0.78 & & -0.03 & 0.82 \\
\hline
\end{tabular}

Note: ${ }^{* *} p<0.01$

Indeed, the decreased expression of LZTFL1 was correlated with low survival rate of non-small cell lung cancer (NSCLC) and recurrence [17]. Kaplan-Meier analysis showed that high expression of LZTFL1 led to longer survival terms than low expression of LZTFL1 in GC patients [8].

In this study the expression of LZTFL1 protein in GC tissue was lower than that in gastritis tissue, and the expression of LZTFL1 protein in GC tissue was significantly correlated with tumor stage and degree of tumor differentiation. Higher degrees of tumor differentiation were associated with higher expressions of LZTFL1. Thus LZTFL1 protein tended to decline as GC worsened.

It was also found that LZTFL1 expression increased with increases in extent of invasiveness. This finding is at variance with those of Wang et al [8] who reported that LZTFL1 suppressed gastric cancer cell migration and invasion. This disparity may be due to sample origin and sample number, and merits further investigations.

The expression levels of LZTFL1 mRNA in the GC patients were lower than in corresponding peri-carcinogenous tissue. In addition, there were no obvious differences in expression levels of LZTFL1 mRNA amongst GC groups with different clinical and pathological features. These results suggest that the processing and modification steps after LZTFL1 gene transcription may influence LZTFL1 protein expression level.

With the aid of laser-scanning confocal microscope, Wei has reported that LZTFL1 and E-cadherin have co-localization features in intestinal epithelial cells with normal differentiation, implying that LZTFL1 may 
stabilize adhesion connection induced by $\mathrm{E}$ cadherin [6]. Wang et al have suggested that cytoplasmic LZTFL1 and E-cadherin inhibit $\beta$ catenin nuclear transport and EMT processes in GC cells, thereby inhibiting their invasion and metastasis[7]. This is in agreement with the results obtained in the present study, in which LZTFL1 protein expression was positively correlated with E-cadherin, and negatively correlated with $\beta$-catenin.

It has been reported that LZTFL1 can regulate Tcell activation and IL-5 levels[18]. The costimulatory signal of $\mathrm{T}$-cell activation process emanates from adhesion effects between the costimulatory signal of T-cell and ligand of antigenpresenting cells. ICAM-1/LFA- 1 is one of them [19]. VCAM-1 is located on the surface of various cells. It participates in metastasis of tumor cells as a co-stimulatory molecule. Therefore, the present study also investigated correlations between LZTFL1, ICAM-1 and VCAM-1. The results showed that LZTFL1 was negatively correlated with ICAM-1 but had no correlation with VCAM-1.

\section{CONCLUSION}

The results obtained in this study demonstrate that LZTFL1 is expressed at low levels in GC, and its expression level decreases with progression of GC. The results also indicate that LZTFL1-induced inhibition of cancer involves the participation of some adhesion proteins. As a suppressor of invasion of cancer cells, LZTFL1 may be a potential target for targeted therapy of gastric cancer.

\section{DECLARATIONS}

\section{Acknowledgement}

This work was funded by Science and Technology Program of Gansu Provincal Academic Institute for Medical Research (no. ykz-2013-5) and the Natural Science Foundation of Gansu Province (no. 145RJZA200).

\section{Conflict of Interest}

No conflict of interest associated with this work.

\section{Contribution of Authors}

The authors declare that this work was done by the authors named in this article and all liabilities pertaining to claims relating to the content of this article will be borne by them.

\section{Open Access}

This is an Open Access article that uses a funding model which does not charge readers or their institutions for access and distributed under the terms of the Creative Commons Attribution License (http://creativecommons.org/licenses/by/ 4.0) and the Budapest Open Access Initiative (http://www.budapestopenaccessinitiative.org/rea d), which permit unrestricted use, distribution, and reproduction in any medium, provided the original work is properly credited.

\section{REFERENCES}

1. Jemal A, Bray F, Center MM, Ferlay J, Ward E, Forman D. Global cancer statistics. CA Cancer J Clin 2011; 61(2): 69.

2. Bertuccio P, Chatenoud L, Levi F, Praud D, Ferlay J, Negri E, Malvezzi M, La VC. Recent patterns in gastric cancer: a global overview. Int J Cancer 2009; 125(3): 666-673.

3. Nagini S. Carcinoma of the stomach: A review of epidemiology, pathogenesis, molecular genetics and chemoprevention. World J Gastrointest Oncol 2012; 4(7): 156-169.

4. Ferlay J, Soerjomataram I, Dikshit R, Eser S, Mathers C, Rebelo M, Parkin DM, Forman D, Bray F. Cancer incidence and mortality worldwide: sources, methods and major patterns in GLOBOCAN 2012. Int J Cancer 2015; 136(5): E359.

5. Wroblewski LE, Peek RM, Wilson KT. Helicobacter pylori and Gastric Cancer: Factors That Modulate Disease Risk. Clin Microbiol Rev 2010; 23(4): 713-739.

6. Nguyen $D X$, Bos $P D$, Massagué J. Metastasis: from dissemination to organ-specific colonization. Nat Rev Cancer 2009; 9(4): 274-284.

7. Wei Q, Zhou W, Wang W, Gao B, Wang L, Cao J, Liu ZP. Tumor-suppressive functions of leucine zipper transcription factor-like 1. Cancer Res 2010; 70(7): 2942-2950.

8. Wang L, Guo J, Wang Q, Zhou J, Xu C, Teng R, Chen Y, Wei Q, Liu ZP. LZTFL1 suppresses gastric cancer cell migration and invasion through regulating nuclear translocation of $\beta$-catenin. J Cancer Res Clin Oncol 2014; 140(12): 1997-2008.

9. Wei $Q$, Zhou W, Wang W, Gao B, Cao J, Wang LB, Liu Z. Abstract LB-8: Tumor suppressive functions of leucine zipper transcription factorlike 1. Cancer Res 2011; 70/8 Supplement): $L B-8-L B-8$.

10. Pinho SS, Seruca R, Gärtner F, Yamaguchi $Y, G u J$, Taniguchi N, Reis CA. Modulation of E-cadherin function and dysfunction by N-glycosylation. Cell Mol Life Sci 2011; 68(6): 1011-1020.

11. Rodriguez FJ, Lewis-Tuffin LJ, Anastasiadis PZ. Ecadherin's dark side: possible role in tumor progression. Biochim Biophys Acta 2012; 1826(1): 23-31. 
12. Nabais S, Machado JC, Lopes C, Seruca R, Carneiro F, Sobrinho-Simões $M$. Patterns of beta-catenin expression in gastric carcinoma: clinicopathological relevance and mutation analysis. Int J Surg Pathol 2003; 11(1): 1-9.

13. Xiu-Wen YU, Gao Y. The expression of $\beta$-catenin in gastric diseases and pathological implications. Natl Med FrontChina 2011; 13: 1-5

14. Meng-Meng, Tian, Zhong-Wu, Ying, Ai-Lian, Zhao, JiYou. Polymorphisms of ICAM-1 are associated with gastric cancer risk and prognosis. World J Gastroenterol 2012; 18(4): 368-374.

15. Schlesinger $M$, Bendas G. Vascular Cell Adhesion Molecule-1 (VCAM-1) - An increasing insight into its role in tumorigenicity and metastasis. Int J Cancer 2015; 136(11): 2504-2514.

16. World Health Organization. Declaration of Helsinki. Br Med J 1996; 313(7070): 1448-1449.
17. Wei $Q$, Chen $Z H$, Wang $L$, Zhang $T$, Duan $L$, Behrens $C$, Wistuba II, Minna JD, Gao B, Luo JH. LZTFL1 suppresses lung tumorigenesis by maintaining differentiation of lung epithelial cells. Oncogene 2016; 35(20): 2655.

18. Jiang $H$, Promchan $K$, Lin BR, Lockett S, Chen, Marshall H, Badralmaa Y, Natarajan V. LZTFL1 Upregulated by All-trans Retinoic Acid during CD4+ $T$ Cell Activation Enhances IL-5 Production. J Immunol 2015; 196(3): 1081.

19. Verma NK, Fazil MH, Ong ST, Chalasani ML, Low JH, Kottaiswamy APP, Kizhakeyil A, Kumar S, Panda AK, Freeley M, Smith SM, Boehm BO, Kelleher D. . LFA1/ICAM-1 Ligation in Human $T$ Cells Promotes Th1 Polarization through a GSK3 $\beta$ Signaling-Dependent Notch Pathway. J Immunol 2016; 197(1): 108. 